\title{
The cytokine network in asthma and chronic obstructive pulmonary disease
}

Peter J. Barnes

National Heart \& Lung Institute, Imperial College London, London, United Kingdom.

\begin{abstract}
Asthma and chronic obstructive pulmonary disease (COPD) are very common inflammatory diseases of the airways. They both cause airway narrowing and are increasing in incidence throughout the world, imposing enormous burdens on health care. Cytokines play a key role in orchestrating the chronic inflammation and structural changes of the respiratory tract in both asthma and COPD and have become important targets for the development of new therapeutic strategies in these diseases.
\end{abstract}

\section{Introduction}

The most common inflammatory diseases of the airways are asthma and chronic obstructive pulmonary disease (COPD), and the incidence of both is increasing throughout the world. The prevalence of asthma in developed countries is approximately $10 \%$ in adults and even higher in children, whereas in developing countries, the prevalence is lower but increasing rapidly. The global prevalence of COPD is approximately $10 \%$ among individuals over the age of 40 years. Asthma often starts in early childhood and is characterized by intermittent wheezing and shortness of breath. In contrast, the predominant symptom in COPD is shortness of breath on exertion, which is persistent and slowly progressive. Although the clinical symptoms of both diseases are caused by airway narrowing as a result of inflammation in the airways, there are marked differences in the patterns of underlying inflammation.

Cytokines play a key role in orchestrating the chronic inflammation of asthma and COPD by recruiting, activating, and promoting the survival of multiple inflammatory cells in the respiratory tract (Figure 1, Figure 2, and Table 1). Over 50 cytokines have now been identified in asthma and COPD, but their role in the pathophysiology of these complex airway diseases is often unclear. For the purpose of this Review, cytokines are classified into lymphokines (cytokines that are secreted by $\mathrm{T}$ cells and regulate immune responses), proinflammatory cytokines (cytokines that amplify and perpetuate the inflammatory process), growth factors (cytokines that promote cell survival and result in structural changes in the airways), chemokines (cytokines that are chemotactic for inflammatory cells), and antiinflammatory cytokines (cytokines that negatively modulate the inflammatory response), although many of these functions may overlap. Where possible, I have focused on human studies and have emphasized any therapeutic interventions that have been made.

\footnotetext{
Nonstandard abbreviations used: AHR, airway hyperresponsiveness; BAL, bronchoalveolar lavage; COPD, chronic obstructive pulmonary disease; FOXP3, forkhead box P3; GATA3, GATA-binding protein 3; IL-1Ra, IL-1 receptor antagonist; IL-4R $\alpha$; $\alpha$-chain of the IL- 4 receptor; NFAT, nuclear factor of activated T cells; NGF, nerve growth factor; Tc1, type 1 cytotoxic T (cells); TSLP, thymic stromal lymphopoietin. Conflict of interest: The author has received research funding from AstraZeneca, Boehringer-Ingelheim, Dainippon-Sumitoma Pharma, Daiichi-Sankyo Co., GlaxoSmithKline, and Novartis, all of which are involved in the development of new treatments for asthma and COPD.

Citation for this article: J. Clin. Invest. 118:3546-3556 (2008). doi:10.1172/JCI36130.
}

\section{Inflammation in asthma and COPD}

Despite the similarity of some clinical features of asthma and COPD, there are marked differences in the pattern of inflammation in the respiratory tract, with different inflammatory cells, mediators, consequences, and responses to therapy (1). In addition, inflammation in asthma predominantly involves the larger airways, whereas in COPD, it involves predominantly small airways and the lung parenchyma. However, patients with severe asthma have airway inflammation that is more similar to that seen in individuals with COPD, suggesting a convergence of cytokine networks.

Bronchial biopsies from asthmatics show infiltration with eosinophils, activated mast cells, and $\mathrm{T}$ cells that are predominantly Th2 cells (Figure 1). There are characteristic structural changes, with collagen deposition under the epithelium (also described as basement-membrane thickening) and increased airway smooth muscle as a result of hyperplasia and hypertrophy. There is also an increase in the number of blood vessels (angiogenesis) as well as mucus hyperplasia. In bronchial biopsies, small airways, and lung parenchyma from patients with COPD, there are an infiltration of T cells (predominantly Th1 and type 1 cytotoxic T [Tc1] cells) and increased numbers of neutrophils and macrophages (Figure 2). Fibrosis around small airways is thought to be a major mechanism contributing to irreversible airway narrowing in individuals with COPD (2). As in asthma, there are mucus hyperplasia and increased expression of mucin genes. A marked difference between COPD and asthma is that destruction of alveolar walls (emphysema) occurs only in COPD; this is a result of protease-mediated degradation of connective tissue elements, particularly elastin, and apoptosis of type I pneumocytes and endothelial cells.

\section{The role of lymphokines and $T$ cell regulatory cytokines in asthma and COPD}

Lymphokines include cytokines that are released predominantly from $T$ cells, which play a critical role in orchestrating inflammation in asthma (Figure 3 ) and are also prominent in the inflammation observed in individuals with COPD. The T cells detected in the inflamed airways of individuals with asthma and COPD secrete distinctive patterns of cytokines that are associated with the different patterns of inflammation seen in these diseases through their roles in recruiting distinct types of inflammatory cells and mediating distinct effects on structural cells in the airways.

Th2 cytokines. In patients with asthma, there is an increase in the number of $\mathrm{CD}^{+}$Th cells in the airways, which are predominantly of the Th2 subtype (1). Th2 cells are characterized by secretion of 


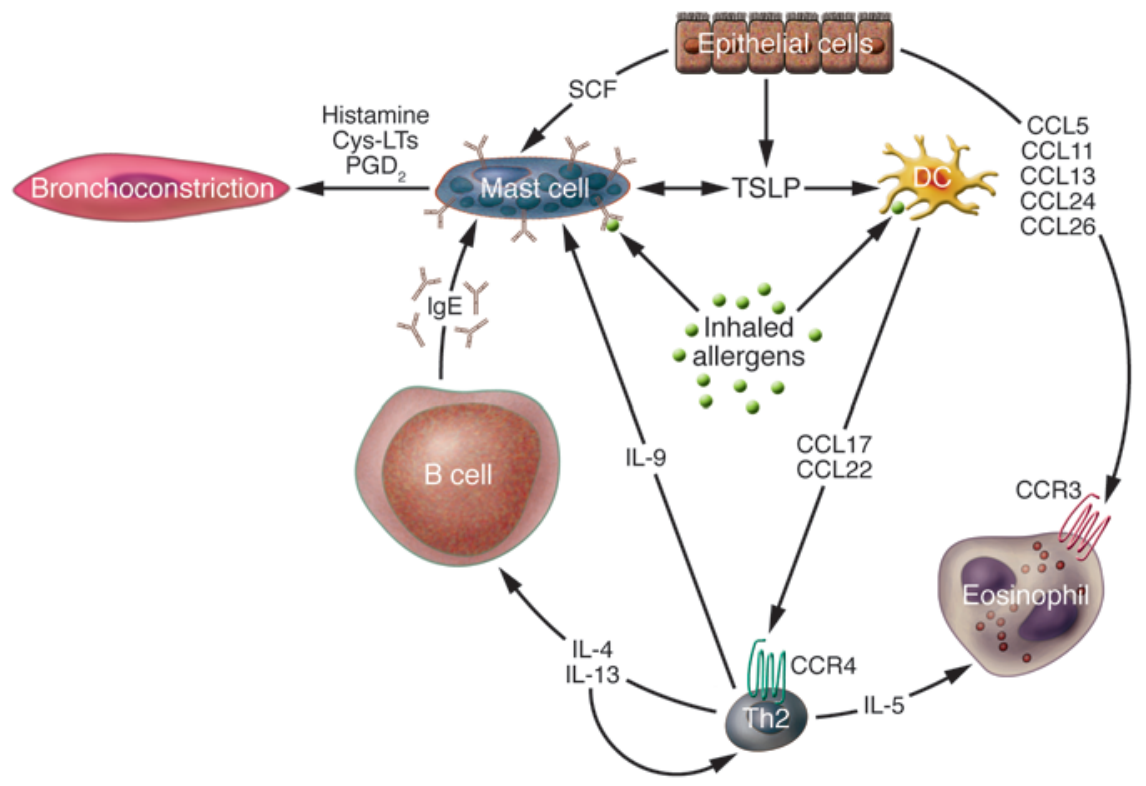

\section{Figure 1}

Cytokines involved in asthma. Epithelial cells play an important role in orchestrating the inflammation of asthma through the release of multiple cytokines, including SCF (which maintains mast cells in the airways), TSLP (which acts on DCs to release the Th2 chemoattractants CCL17 and CCL22, which act via CCR4), and several chemokines that attract eosinophils by activating CCR3. Th2 cells orchestrate the inflammatory response in asthma through the release of IL-4 and IL-13 (which stimulate $B$ cells to synthesize lgE), IL-5 (which is necessary for eosinophilic inflammation), and IL-9 (which stimulates mast cell proliferation). Mast cells are thus orchestrated by several interacting cytokines and play an important role in asthma through the release of the bronchoconstrictor mediators histamine, cysteinyl-leukotrienes (Cys-LTs), and $\mathrm{PGD}_{2}$. Adapted with permission from Nature Publishing Group (1).
IL-4, IL-5, IL-9, and IL-13. The transcription factor GATA-binding protein 3 (GATA3) is crucial for the differentiation of uncommitted naive T cells into Th2 cells and regulates the secretion of Th2 cytokines (3). There is an increase in the number of GATA3 ${ }^{+} \mathrm{T}$ cells in the airways of stable asthmatic subjects (4). Following ligation of the TCR and CD28 coreceptor by APCs, GATA3 is phosphorylated and activated by p38 MAPK, resulting in translocation from the cytoplasm to the nucleus, where it activates transcription of genes characteristic of Th2 cells (5). Nuclear factor of activated T cells (NFAT) is a $\mathrm{T}$ cell-specific transcription factor and enhances the transcriptional activation of the Il4 promoter by GATA3 (3). Finally, IL-33, a member of the IL-1 family of cytokines, promotes differentiation of Th2 cells by translocating to the nucleus and regulating transcription through an effect on chromatin structure (6), but it also acts as a selective chemoattractant of Th2 cells (7). Although COPD is viewed as a disease of type 1 immunity (1), Th2 cytokines may also be increased in COPD patients; for example, increased IL-4 expression is seen in $\mathrm{CD}^{+} \mathrm{T}(\mathrm{Tc} 2)$ cells from bronchoalveolar lavage (BAL) fluid (8).

IL-4 plays a critical role in the differentiation of Th2 cells from uncommitted Th0 cells and may be important in initial sensitization to allergens. It is also important for isotype switching of $\mathrm{B}$ cells from producers of IgG to producers of IgE. IL-13 mimics IL-4 in inducing IgE secretion and causing structural changes in the airways but does not play a role in promoting Th2 cell differentiation (9). IL-13 signals through a heterodimeric receptor comprising the $\alpha$-chain of the IL-4 receptor (IL-4R $\alpha$ ) and a specific IL-13-binding chain (IL-13R $\alpha$ ); the use of IL-4R $\alpha$ accounts for some of the shared effects of IL-4 and IL-13, which are mediated via activation of STAT6. IL-13 also binds to another receptor (IL-13R $\alpha 2$ ), which does not appear to signal and acts as a decoy receptor. IL-13 has attracted particular attention as a therapeutic target for the treatment of asthma, as it not only induces airway hyperresponsiveness (AHR) in animal models of asthma but also produces several of the structural changes seen in chronic asthma, including goblet cell hyperplasia, airway smooth muscle proliferation, and subepithelial fibrosis (9). IL-13 induces inflammation through stimulating the expression of multiple chemokines, including CCL11 (also known as eotaxin) from structural cells in the airways, including epithelial cells. IL-13 induces AHR and mucus hypersecretion by activating STAT6 in the airway epithelium (10), which increases expression of acid mammalian chitinase (AMC) (11). Indeed, neutralization of AMC inhibits IL-13-mediated AHR and Th2-driven inflammation. IL-13 is produced by several cell types in addition to Th2 cells, including other types of T cells (Th1 cells, Tc2 cells, and invariant NKT cells) and inflammatory cells (mast cells, basophils, and eosinophils). IL-13 shows increased expression in the airways of asthmatic patients, whereas it is reduced in patients with severe COPD (12). After allergen challenge, there is a transient increase in IL-4 in BAL fluid, whereas the secretion of IL-13 is sustained and correlates with the increase in the number of eosinophils in the airways (13). Further, levels of a chitinase-like protein are increased in the lungs and serum of patients with severe asthma, possibly reflecting increased IL-13 secretion (14). Pitrakinra, a mutated form of IL-4 that blocks the binding of IL-4 and IL-13 to IL-4R $\alpha$, reduces the late response to inhaled allergen in asthmatic patients after either inhaled or subcutaneous administration (15).

IL-5 plays a key role in inflammation mediated by eosinophils, since it is critically involved in the differentiation of eosinophils from bone marrow precursor cells and also prolongs eosinophil survival. Systemic and local administration of IL-5 to asthmatic patients results in an increase in circulating eosinophils and $\mathrm{CD}^{+} 4^{+}$eosinophil precursors (16). In experimental animals, blocking antibodies specific for IL-5 reduces eosinophil numbers in the lungs and inhibits allergen responses. However, in asthmatics, a humanized blocking antibody specific for IL-5 (mepolizumab) markedly reduces circulating and sputum eosinophils but has no effect on allergen responses or AHR. In symptomatic asthmatics, mepolizumab has no clinical benefit, despite a marked reduction in circulating eosinophils (17). However, mepolizumab does not completely eliminate eosinophils from the airways, which may explain why it provides no clinical benefit (18).

IL-9 overexpression in mice induces inflammation mediated by eosinophils, mucus hyperplasia, mastocytosis, AHR, and increased expression of other Th2 cytokines and IgE (19). IL-9 blockade inhibits pulmonary eosinophilia, mucus hypersecretion, and AHR 


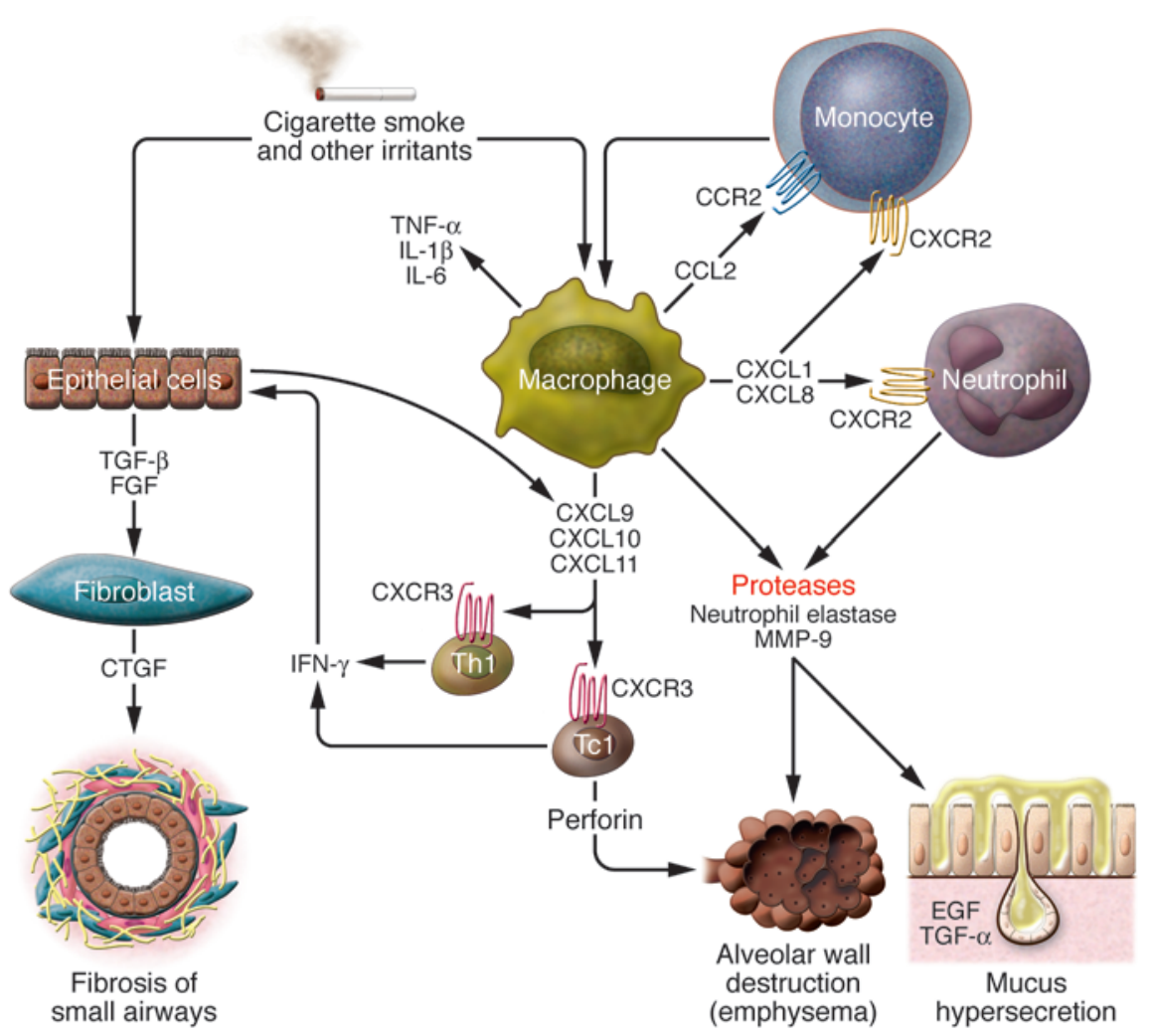

\section{Figure 2}

Cytokines involved in COPD. Inhaled irritants, such as cigarette smoke, activate epithelial cells and macrophages to release multiple cytokines, including growth factors such as TGF- $\beta$ and FGFs, which stimulate fibroblast proliferation, resulting in fibrosis in the small airways. These cells also secrete the proinflammatory cytokines TNF- $\alpha, \mathrm{IL}-1 \beta$, and IL-6, all of which amplify inflammation, and several chemokines that attract circulating cells into the lungs. CCL2 acts via CCR2 to attract monocytes (which differentiate into macrophages in the lungs); CXCL1 and CXCL8 act via CXCR2 to attract neutrophils and monocytes; and CXCL9, CXCL10, and CXCL11 act via CXCR3 to attract Th1 cells and Tc1 cells, both of which release IFN- $\gamma$, which in turn stimulates the release of more of these CXCR3-binding chemokines. Mucus hypersecretion is stimulated by EGF and TGF- $\alpha$. CTGF, connective tissue growth factor. Adapted with permission from Nature Publishing Group (1). after allergen challenge of sensitized mice. Asthmatic patients show increased expression of IL-9 and its receptor in the airways (19). Many of the effects of IL-9 in mice (eosinophilic inflammation and mucus hypersecretion) are mediated via the release of IL-13, whereas its effects on mast cell expansion and B cells seem to be direct (20). IL-9 plays an important role in differentiation and proliferation of mast cells and interacts synergistically with SCF.

Th1 and Tc1 cytokines. The transcription factor T-bet is crucial for Th1 cell differentiation and secretion of the Th1-type cytokine IFN- $\gamma$. Consistent with the prominent role of Th 2 cells in asthma, $\mathrm{T}$-bet expression is reduced in $\mathrm{T}$ cells from the airways of asthmatic patients compared with airway $T$ cells from nonasthmatic patients (21). After phosphorylation, T-bet associates with and inhibits the function of GATA3 by preventing it from binding to its DNA target sequences (22). In turn, GATA3 inhibits the production of Th1-type cytokines by inhibiting STAT4, the main transcription factor activated by the T-bet-inducing cytokine IL-12 (23). Th1 cells are the prominent $\mathrm{CD} 4^{+} \mathrm{T}$ cells, and $\mathrm{Tc} 1$ cells the predominant $\mathrm{CD}^{+} \mathrm{T}$ cells expressed in COPD lungs (24), but their role in the pathogenesis of COPD is not yet certain.

IFN- $\gamma$ is the predominant cytokine produced by Th 1 and Tc1 cells and may play an important role in inflammation in individuals with COPD by inducing the release of chemokines. In contrast, it is usually found at reduced levels in individuals with asthma, although levels of IFN- $\gamma$ are increased in patients with more severe disease and acute exacerbations (25). IFN- $\gamma$ activates T-bet via STAT1, resulting in expression of genes encoding Th1 cytokines and suppression of genes encoding Th2 cytokines (26). IFN- $\gamma$ also orchestrates the infiltration of Th1 and Tc1 cells in the lungs of individuals with COPD through the upregulation of the chemokine receptor CXCR3 on these cells and the release of the CXCR3- activating chemokines CCL9 (also known as Mig), CCL10 (also known as IP-10), and CCL11 (also known as I-TAC) (24). Consistent with this, there is an increase in the number of $\mathrm{T}$ cells secreting IFN- $\gamma$ in the airways of patients with COPD (27).

Type I and type III IFNs. Type 1 IFNs (IFN- $\alpha$ and IFN- $\beta$ ) and type III IFNs (IFN- $\lambda$ ) play an important role in innate immunity against viral infections, but IFN- $\beta$ and IFN- $\lambda$ show reduced expression in epithelial cells of asthmatic patients and are associated with increased rhinovirus replication, which may predispose these patients to viral exacerbations of asthma $(28,29)$. The molecular mechanism for these defects in innate immunity is not yet understood. Low-dose IFN- $\alpha$ seems to give marked benefit in patients with severe corticosteroid-resistant asthma but again the mechanism is unknown (30).

IL-12 and related cytokines. IL-12 plays an important role in differentiating and activating Th 1 cells and is produced by activated macrophages, DCs, and airway epithelial cells (31). IL-12 induces $\mathrm{T}$ cells to release IFN- $\gamma$, which regulates the expression of IL-12R $\beta 2$ and so maintains the differentiation of Th1 cells, whereas IL-4 suppresses IL-12R $\beta 2$ expression and thus antagonizes Th1 cell differentiation. IL-12 levels released from whole-blood cells are lower in asthmatic patients, indicating a possible reduction in IL-12 secretion (32). In patients with mild asthma, recombinant IL-12 causes a progressive fall in circulating eosinophils but no reduction in allergen response or AHR, as with mepolizumab (the humanized blocking antibody specific for IL-5) (33). IL-12 is a heterodimer comprising p40 and p35 subunit; the p40 subunit is also a component of IL-23. The p40 subunit can also homodimerize to form IL-12p80, and both monomeric p40 and IL-12p80 can act as functional antagonists of IL-12 and IL-23 by binding to IL-12R $\beta 1$ (34). However, they can also have 


\section{Table 1}

Key cytokines involved in asthma and COPD

\begin{tabular}{|c|c|c|c|c|}
\hline Cytokine & Effect in asthma & Effect in COPD & Main mechanism underlying effects & References \\
\hline \multicolumn{5}{|c|}{ Lymphokines and T cell regulatory cytokines } \\
\hline IL-4 & Enhances disease & Might enhance disease & $\begin{array}{l}\text { Increases production of IgE; } \\
\text { increases number of Th2 cells }\end{array}$ & $1,8,13$ \\
\hline IL-5 & Enhances disease & Unknown & Increases number of eosinophils & 16 \\
\hline IL-9 & Enhances disease & Unknown & Increases number of mast cells & 19 \\
\hline IL-12 & Reduces disease & Enhances disease & Increases number of Th1 cells & 31,32 \\
\hline IL-13 & Enhances disease & Reduces disease & $\begin{array}{l}\text { Increases production of IgE; } \\
\text { induces airway remodeling }\end{array}$ & $9-11,13$ \\
\hline IL-17 & Enhances disease & Unknown & Indirectly increases number of neutrophils & $41-46$ \\
\hline IL-18 & Reduces disease & Enhances disease & Increases IFN- $\gamma$ release & 35,36 \\
\hline IL-25 & Enhances disease & Unknown & Increases number of Th2 cells & 47,48 \\
\hline IFN- $\gamma$ & Reduces disease & Enhances disease & Decreases number of Th2 cells & 26 \\
\hline \multicolumn{5}{|c|}{ Proinflammatory cytokines } \\
\hline IL-1 $\beta$ & Enhances disease & Enhances disease & Increases inflammation & 57 \\
\hline IL-6 & Enhances disease & Enhances disease & Increases inflammation & 60 \\
\hline TNF- $\alpha$ & Enhances severe disease & Enhances disease & Increases inflammation & 50,51 \\
\hline TSLP & Enhances disease & Unknown & Increases number of Th2 cells & $61-64$ \\
\hline \multicolumn{5}{|l|}{ Growth factors } \\
\hline EGF & Enhances disease & Enhances disease & Induces mucus hypersecretion & $80-82$ \\
\hline GM-CSF & Enhances disease & Enhances disease & $\begin{array}{l}\text { Increases number of neutrophils; } \\
\text { increases number of eosinophils }\end{array}$ & 65,66 \\
\hline NGF & Enhances disease & Unknown & Increases AHR & 71,72 \\
\hline SCF & Enhances disease & Unknown & Increases number of mast cells & 67 \\
\hline TGF- $\beta$ & Enhances severe disease & Enhances disease & Increases fibrosis; suppresses inflammation (Tregs) & $73-79$ \\
\hline VEGF & Enhances disease & Reduces disease & Induces angiogenesis; increases vascular leakage & $83-86$ \\
\hline \multicolumn{5}{|l|}{ Chemokines } \\
\hline CCR2 agonists & Enhances disease & Enhances disease & Increases number of monocytes & 89,90 \\
\hline CCR3 agonists & Enhances disease & Enhances exacerbations & Increases number of eosinophils & $91-94$ \\
\hline CCR4 agonists & Enhances disease & Unknown & Increases number of Th2 cells & 92,95 \\
\hline CCR5 agonists & Enhances disease & Enhances disease & $\begin{array}{l}\text { Increases number of T cells; } \\
\text { increases numbers of eosinophils }\end{array}$ & $97-99$ \\
\hline CXCR2 agonists & Enhances severe disease & Enhances disease & $\begin{array}{l}\text { Increases number of neutrophils; } \\
\text { increases number of monocytes }\end{array}$ & $90,101-103$ \\
\hline CXCR3 agonists & Enhances severe disease & Enhances disease & $\begin{array}{l}\text { Increases number of Th1 cells; } \\
\text { increases number of Tc1 cells }\end{array}$ & $97,104-107$ \\
\hline \multicolumn{5}{|c|}{ Antiinflammatory cytokines } \\
\hline $\mathrm{IL}-10$ & Decreases disease & Decreases disease & Decreases inflammation & $112-116$ \\
\hline
\end{tabular}

proinflammatory effects through activating IL-12R $\beta 1$, resulting in effects such as macrophage chemoattraction (34). Most of the effects of IL-12 are mediated via activation of STAT4, which is phosphorylated in the airways and BAL fluid lymphocytes of patients with COPD (27).

Originally described as IFN- $\gamma$-releasing factor, IL-18 has a mechanism of action different from that of IL-12 and may enhance Th1 responses independently of IL-12 (35). IL-12 and IL-18 appear to have a synergistic effect on the induction of IFN- $\gamma$ release and the inhibition of IL-4-dependent IgE production and AHR. In individuals with COPD, IL-18 expression is increased in alveolar macrophages and $\mathrm{CD}^{+} \mathrm{T}$ cells in the airways and is correlated with disease severity (36).

IL-27 is a member of the IL-12 family that promotes Th1 cell differentiation through a STAT1-dependent mechanism independently of IL-12 (37). It is produced by activated APCs and enhances Th1 function by downregulating GATA3 expression and upregu- lating T-bet expression, thereby favoring the production Th1-type cytokines, which then act to further inhibit GATA3 expression (38). The role of IL-27 in asthma and COPD remains to be determined.

Th17 cytokines. Th17 cells are a subset of $\mathrm{CD}^{+} \mathrm{T}$ cells that play an important role in inflammatory diseases and are regulated by the transcription factor retinoic acid orphan receptor- $\gamma t$ (ROR $\gamma \mathrm{t})$ (39). IL-6, IL-1 $\beta$, TGF- $\beta$, and IL-23 are all involved in the differentiation of human Th17 cells $(39,40)$. Little is known about the role of Th17 cells in either asthma or COPD, but levels of IL-17A (the predominant product of Th17 cells) are increased in the sputum of individuals with asthma (41) and Th17 cells are increased in the airways of asthmatic subjects (42). IL-17A and the closely related IL-17F are linked to neutrophil-mediated inflammation by induction of the release of the neutrophil chemoattractants CXCL1 and CXCL8 from airway epithelial cells and airway smooth muscle cells (43) and thereby may play a role in the neutrophilic inflammation of severe asthma and COPD (44). IL-17 also increases the expres- 


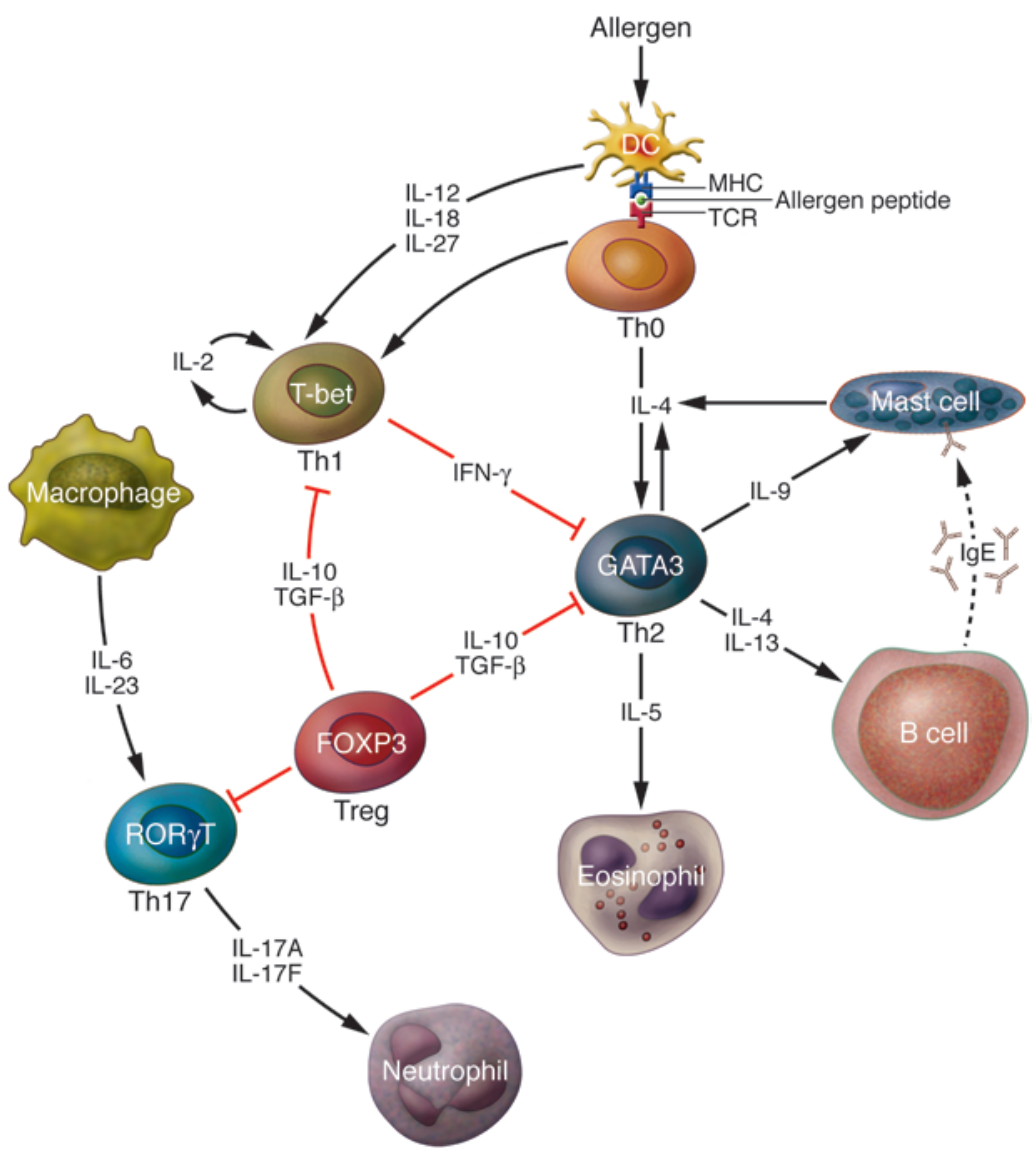

Figure 3

Th cells in airways. Th2 cells predominate in most patients with asthma and differentiate from uncommitted precursor T cells under the influence of IL-4. Th2 cells orchestrate allergic inflammation through the release of the Th2 cytokines IL-4, IL-5, IL-9, and IL-13. Th1 cells differentiate under the influence of IL-12 and IL-27 and suppress Th2 cells through the release of IFN- $\gamma$. Th17 cells differentiate under the influence of IL- 6 and IL-23. Tregs normally suppress other Th cells through the release of TGF- $\beta$ and IL-10 and may have impaired function in asthma. Each Th cell type is regulated by a specific transcription factor: T-bet for Th1 cells, GATA3 for Th2 cells, retinoic acid orphan receptor- $\gamma \mathrm{t}(\mathrm{ROR} \gamma \mathrm{t})$ for Th17 cells, and FOXP3 for Tregs. sion of mucin-encoding genes (MUC5AC and MUC5B) in human airway epithelial cells (45). However, the functional role of IL-17 in asthma is unclear, as it seems to be involved in allergic sensitization of animal models but to inhibit eosinophilic inflammation in sensitized animals (44).

Th17 cells also produce IL-21, which is important for the differentiation of these cells and thus acts as a positive autoregulatory factor (46). It also inhibits expression of the forkhead transcription factor forkhead box P3 (FOXP3) and thereby the development of Tregs (46). IL-22 is also released by Th17 cells and stimulates the production of IL-10 and acute-phase proteins. More work is needed to understand the role and regulation of Th17 cells in asthma and COPD, as they may provide important new targets for future therapy.

IL-25 (also known as IL-17E), another member of the IL-17 superfamily, is produced by Th2 cells, mast cells, and epithelial cells. IL-25 induces the expression of IL-4, IL-5, and IL-13, resulting in inflammation mediated by eosinophils, increased IgE production, and AHR in mice (47). It also enhances Th2 cytokine secretion from human Th2 cells (48). A blocking antibody specific for IL-25 inhibits the development of AHR in response to allergens in mice and is in clinical development for asthma (49).

\section{The role of proinflammatory cytokines in asthma and COPD}

Proinflammatory cytokines, such as TNF- $\alpha$, IL-1 $\beta$, and IL-6, are found in increased amounts in the sputum and BAL fluid in individuals with asthma and COPD and amplify inflammation, in part through the activation of NF- $\mathrm{KB}$, which leads to the increased expression of multiple inflammatory genes. In other chronic inflammatory diseases, such as rheumatoid arthritis and inflammatory bowel diseases, blocking these cytokines has proven to be of clinical benefit, so there has been considerable interest in determining whether the same approach might also be useful in inflammatory airway diseases.

TNF- $\alpha$. Many cells have the capacity to secrete TNF- $\alpha$, including macrophages, mast cells, T cells, epithelial cells, and airway smooth muscle cells. Inhaled TNF- $\alpha$ induces AHR and airway inflammation mediated by neutrophils in normal subjects (50). TNF- $\alpha$ acts directly on human airway smooth muscle to increase the contractile response to spasmogens and may thus play a role in the AHR of asthma. TNF- $\alpha$ is expressed in various cells in asthmatic airways, particularly mast cells, and may play a key role in amplifying asthmatic inflammation through the activation of NF- $\mathrm{KB}$ (51). Blocking TNF- $\alpha$ with etanercept (a fusion protein comprising human soluble TNFR linked to the Fc component of human IgG1) reduced AHR and improved lung function in a small study of patients with refractory asthma (52). In addition, blocking TNF- $\alpha$ with infliximab (a chimeric antibody specific for human TNF- $\alpha$ ) reduced exacerbations in a patients with moderate asthma (53). Larger studies are now underway in patients with severe asthma.

In patients with COPD, TNF- $\alpha$ levels are increased in sputum induced by inhalation of hypertonic saline, particularly during exacerbations (54). Furthermore, COPD patients with weight loss show increased TNF- $\alpha$ release from circulating cells. However, infliximab failed to provide patients with COPD any benefit, as assessed by effects on symptoms, lung function, and exercise per- 
formance, when administrated at the doses that are effective in individuals with rheumatoid arthritis (55). It was also without effect in patients with severe COPD who have cachexia (56). These surprising findings may indicate that the drug does not adequately neutralize local concentrations of TNF- $\alpha$ or that other cytokines are more important. Further, in COPD patients treated with drugs that block the function of TNF- $\alpha$, there was an increase in the incidence of chest infections and cancers, raising concerns that suppression of TNF- $\alpha$ may be detrimental in patients with COPD who are already predisposed to bacterial lung infections and cancer.

$I L-1 \beta$. IL-1 $\beta$ expression is increased in the airways of asthmatic individuals and activates many inflammatory genes that are expressed in asthma. IL-1 receptor antagonist (IL-1Ra) administration reduces AHR induced by allergens in mice, but human recombinant IL-1Ra (anakinra) is not effective in the treatment of asthma (57). IL-1 $\beta$ markedly activates macrophages from patients with COPD to secrete inflammatory cytokines, chemokines, and MMP9 (58), and studies investigating the efficacy of an antibody that blocks IL- $1 \beta$ in patients with COPD are currently in progress.

IL-6. IL-6 often works in concert with other cytokines and provides a link between innate and acquired immunity. IL- 6 is found in increased amounts in induced sputum of asthmatic patients after mast cell activation (59). It may play a role in the expansion of Th2 and Th17 cells and therefore have a proinflammatory effect in asthma. IL- 6 is found in increased amounts in the sputum, exhaled breath, and plasma of patients with COPD, particularly during exacerbations (60). IL-6 releases C-reactive protein from the liver and may be involved in some of the systemic features of COPD, such as muscle weakness and endothelial dysfunction.

Thymic stromal lymphopoietin. Thymic stromal lymphopoietin (TSLP) is a cytokine belonging to the IL-7 family that shows a marked increase in expression in airway epithelium and mast cells of asthmatic patients (61). TSLP is released from airway epithelial cells, and its synergistic interaction with IL-1 $\beta$ and TNF- $\alpha$ results in the release of Th2 cytokines from mast cells independently of T cells (62). TSLP also plays a key role in programming airway DCs to release the Th2 chemoattractants CCL17 and CCL22 and thus is important in recruiting Th2 cells to the airways (63). TSLP may also directly stimulate Th2 cytokine release from $\mathrm{CD}^{+} \mathrm{T}$ cells. OX40 ligand plays an important role in mediating TSLP-induced allergic inflammation, as blocking antibodies specific for this receptor completely inhibit TSLP-induced activation of Th2 cells in mice and nonhuman primates (64). Because TSLP is an upstream cytokine, through its ability to regulate Th 2 cells, it is a logical target for inhibition in the treatment of asthma.

\section{Growth factors}

Several cytokines implicated in airway inflammation either promote the differentiation and survival of inflammatory cells or result in proliferation and/or activation of structural cells, contributing to airway remodeling. As a result of these functions, they are classified in this Review as growth factors.

GM-CSF. GM-CSF plays a role in the differentiation and survival of neutrophils, eosinophils, and macrophages and has been implicated in asthma and COPD. Its receptor comprises an $\alpha$-chain that is specific for the receptor for GM-CSF and a $\beta$-chain that is also part of the receptors for IL-3 and IL-5. GM-CSF is secreted predominantly by macrophages, epithelial cells, and T cells in response to inflammatory stimuli. Airway epithelial cells of asthmatic patients strongly express GM-CSF, which may condition DCs to direct Th2 immunity and to prolong the survival of eosinophils (65). In COPD, GM-CSF is released by alveolar macrophages and may be important for increased survival of neutrophils and macrophages in the airways (58). Increased concentrations of GM-CSF in BAL fluid of COPD patients, particularly during exacerbations, are correlated with the increased numbers of neutrophils (66).

SCF. SCF is the ligand of the c-Kit tyrosine kinase receptor, which is expressed by several structural and inflammatory cells in the airways (67). SCF is produced by epithelial cells, airway smooth muscle cells, endothelial cells, fibroblasts, mast cells, and eosinophils. It is a critical growth factor for mast cells and promotes their generation from $\mathrm{CD}_{3} 4^{+}$progenitors. SCF induces mast cell survival, adhesion, chemotaxis, degranulation, which releases histamine and tryptase, and synthesis of proinflammatory cytokines and chemokines. SCF is upregulated by inflammatory stimuli and shows increased expression in airway epithelial cells of individuals with asthma (67). SCF induces AHR in mice, and a blocking antibody specific for SCF inhibits inflammation mediated by eosinophils and AHR after allergen exposure (68). Imatinib, a small molecule inhibitor of c-Kit, inhibits allergen-induced pulmonary inflammation and AHR in sensitized mice (69). No blocking studies have so far been reported in individuals with asthma, but blocking antibody specific for SCF reduces the in vitro mast cell chemotactic activity in BAL fluid of asthmatics (70).

Neurotrophins. Neurotrophins are cytokines that play an important role in the function, proliferation, and survival of autonomic nerves. In sensory nerves, neurotrophins increase responsiveness and expression of tachykinins. Nerve growth factor (NGF) may be produced by mast cells, lymphocytes, macrophages, and eosinophils as well as structural cells, such as epithelial cells, fibroblasts, and airway smooth muscle cells. Although neurotrophins have predominant effects on neuronal cells, they can also act as growth factors for inflammatory cells, such as mast cells, as well as increasing chemotaxis and survival of eosinophils $(71,72)$. NGF induces AHR in various animal models of asthma, including guinea pig, mouse, and rat models, and this induction is blocked by antibodies specific for either NGF or its receptor TrkA (71). NGF levels are increased in BAL fluid of asthmatic patients with a further increase after allergen challenge.

TGF- $\beta$. TGF- $\beta$ is a family of pleiotropic cytokines that may play several roles in asthma and COPD. TGF- $\beta$ is a multifunctional growth factor that induces the proliferation of fibroblasts and airway smooth muscle cells, deposition of ECM, and epithelial repair. It is generated from a latent precursor through oxidative stress and various proteases. TGF- $\beta$ also has immunoregulatory effects that are largely mediated through Tregs through the induction of FOXP3, resulting in suppression of Th1 and Th2 cells (73). There is increased expression of TGF- $\beta 1$, particularly in eosinophils in asthmatic airways, and this has been associated with subepithelial fibrosis (74). Increased expression of TGF- $\beta 2$ has also been reported in patients with severe asthma (75). In COPD there is increased expression of TGF- $\beta$ by airway epithelial cells from small airways and macrophages $(76,77)$. Gene-array studies of small airways from COPD patients have shown increased expression of molecules associated with TGF- $\beta$ activation, including thrombospondin and urokinase plasminogen activator (78). Many of the fibrotic effects of TGF- $\beta$ are mediated via increased secretion of connective tissue growth factor (CTGF), which shows increased expression in microarray analysis of COPD lungs (79). 
EGF. EGF activates EGFR tyrosine kinases that are also activated by TGF- $\alpha$ and may play a critical role in regulating mucus secretion in individuals with asthma and COPD. In human airway epithelial cells, EGFR can be activated by oxidative stress, which activates TNF- $\alpha$-converting enzyme (TACE, also known as ADAM-17). TACE cleaves membrane-bound TGF- $\alpha$ to release the soluble cytokine, which results in EGFR phosphorylation and subsequent expression of mucin genes (MUC5AC and MUC5B) (80). EGFR expression is increased in airway epithelial cells of patients with asthma and is related to increased MUC5A/C expression (81). In the airways of individuals with COPD, there is increased expression of EGFR, EGF, and the related cytokine heregulin in airway epithelial cells (82).

$V E G F$. VEGF plays an important role in regulating the growth of new vessels and vascular leakage in asthmatic airways (83). Increased expression of VEGF and VEGF receptors is correlated with increased vascularity in asthmatic airways (84). In contrast, VEGF concentrations are reduced in the lungs and sputum of patients with COPD (85). Furthermore, blockage of VEGF receptors induces apoptosis of alveolar endothelial cells and development of emphysema (86).

\section{Chemokines}

Chemokines play an important role in the recruitment of inflammatory cells from the circulation to the airways in both asthma and COPD (87). There has been particular interest in the role of chemokines in asthma and COPD, as they signal through GPCRs, for which small molecule antagonists can be relatively easily developed (88). Chemokines are best discussed in light of the receptors to which they bind, and these are divided into receptors for CC chemokines (CCRs), receptors for CXC chemokines (CXCRs), and the receptor for the lone $\mathrm{CX} 3 \mathrm{C}$ chemokine.

CCRs. CCL2 (also known as MCP-1) activates CCR2 on monocytes and T cells. CCL2 levels are increased in the sputum, BAL fluid, and lungs of patients with COPD, and CCL2 is also expressed by alveolar macrophages, $\mathrm{T}$ cells, and epithelial cells $(89,90)$. CCL2 is a potent chemoattractant of monocytes and may therefore be involved in the accumulation of macrophages in the lungs of COPD patients.

CCR3 is expressed predominantly on eosinophils and mediates the chemotactic response to several chemokines, including CCL11, CCL24 (also known as eotaxin-2), CCL26 (also known as eotaxin-3), CCL13 (also known as MCP-4), and CCL5 (also known as RANTES), all of which show increased expression in the airways of individuals with asthma (91). Small molecule antagonists of CCR3 are effective in inhibiting pulmonary eosinophilic inflammation in mice exposed to allergen CCR3 and may also be important in the differentiation of eosinophils and their release from bone marrow (92). Further, CCR3 is also expressed on Th2 cells and mast cells in humans. Although most attention has focused on CCL11, CCL24 and CCL26 may play a role in prolonged eosinophilia after allergen exposure (93). CCL11 and CCR3 are also upregulated in the airways of patients with exacerbations of chronic bronchitis and may account for the increased sputum eosinophilia seen in some of these patients (94). Several CCR3 antagonists have been developed for clinical studies in asthma, although so far all have failed for toxicological reasons.

CCR 4 is selectively expressed on Th2 cells and activated by CCL22 and CCL17, which are released from airway epithelial cells and DCs in asthmatic airways (61) and are further increased in BAL fluid after inhaled allergen challenge in association with increased Th2 cytokines (95). CCL8 is also expressed on Th2 cells but neither it nor its ligand CCL1 (also known as I-309) are increased in asthmatic airways (61).

CCR5 is activated by CCL3 (also known as MIP-1 $\alpha$ ), CCL4 (also known as MIP-1 $\beta$ ), and CCL5, all of which are elevated in the lungs of individuals with COPD. T cells expressing CCR5 are increased in the airways of patients with mild to moderate COPD (96) and in the sputum of patients with COPD (97). CCR5 is selectively expressed on Th1 and Tc1 cells and contributes to the recruitment of these cells into the airways of patients with COPD (24). Increased expression of CCL5 in airways and sputum of patients with COPD during exacerbations suggests a role for CCR5 in the recruitment of T cells, eosinophils, and macrophages during exacerbations (98). CCL5 also shows increased expression in asthmatic airways, particularly in airway epithelial and smooth muscle cells (99). CCR5 antagonists are now available for the treatment of HIV/AIDS but have not yet been tested in individuals with either asthma or COPD.

CXCRs. CXCL8 activates CXCR1, which is almost specific for this chemokine, and CXCR2, which is also activated by several related CXC chemokines, including CXCL1 (also known as GRO- $\alpha$ ) and CXCL5 (also known as ENA-78). CXCL1 and CXCL8 levels are markedly increased in induced sputum of patients with COPD and correlate with the increased proportion of neutrophils (90). CXCL8 is further increased during exacerbations of COPD (54), and CXCL5 shows a markedly increased expression in airway epithelium during a COPD exacerbation (100). Small molecule inhibitors of CXCR2, such as SB 225002, block the chemotactic response of neutrophils and monocytes to CXCL8 and CXCL1 in animals in vivo and are now in clinical development for COPD (101). CXCL8 is also increased in the airways and sputum of patients with severe asthma (102) and during virally induced asthma exacerbations (103); it is correlated with increased numbers of neutrophils in the sputum.

$\mathrm{T}$ cells in the peripheral airways of patients with COPD show increased expression of CXCR3 (24), which is activated by CXCL9, CXCL10, and CXCL11, all of which are induced by IFN- $\gamma$. These CXCR3 chemokines are increased in sputum from patients with COPD and correlate with disease severity (97). There is increased expression of CXCL10 by bronchiolar epithelial cells and smooth muscle cells in the small airways of patients with COPD (104). Since Tc1 and Th 1 cells produce IFN- $\gamma$ in COPD, this provides a potential amplification loop to perpetuate $T$ cell accumulation in the lungs. The role of CXCR3 chemokines in asthma is less well established, but CXCL10 produced by airway smooth muscle cells appears to attract mast cells, which express CXCR3, and so may account for the increased numbers of mast cells in airway smooth muscle of asthmatics (105). CXCR3 may also play a role in the recruitment of $\mathrm{T}$ cells following allergen challenge (106). On the other hand, CXCR3 ligands antagonize CCR3, suggesting that they might suppress eosinophilic inflammation (107).

CXCR4 is preferentially expressed on Th2 cells and is activated by CXCL12 (also known as SDF-1 $\alpha$ ). A small molecule inhibitor of CXCR4 (AMD3100) reduces inflammation and AHR in sensitized mice exposed to inhaled allergen, and these effects are associated with a reduction in Th2 cytokines (108). CCL12 may also be involved in mobilization of eosinophil progenitor cells from the bone marrow, as eosinophils express CXCR4 (92).

CX3CR1. CX3CL1 (also known as fractalkine), the sole member of a third family of $\mathrm{CX} 3 \mathrm{C}$ chemokines, is produced by airway epithelial cells after stimulation with TNF- $\alpha$, IL-1 $\beta$, and IFN- $\gamma$ (109). 
Table 2

Cytokine modulators in clinical development for asthma and COPD

\begin{tabular}{|c|c|c|c|c|}
\hline Cytokine & Therapy & Effect in clinical study & Stage of development & References \\
\hline \multirow[t]{2}{*}{ IL-1 } & $\begin{array}{l}\text { Recombinant nonglycosylated } \\
\text { human IL-1Ra (anakinra) }\end{array}$ & No effect in asthma & $\begin{array}{l}\text { Development for asthma halted; } \\
\text { licensed to treat other diseases }\end{array}$ & 57 \\
\hline & Humanized blocking mAb specific for IL-1 $\beta$ & NA & In early clinical trials for COPD & 126 \\
\hline \multirow[t]{2}{*}{ IL-4 } & $\begin{array}{l}\text { Soluble recombinant human IL-4 receptor (Nuvance) } \\
\text { Mutated IL-4 (pitrakinra) }\end{array}$ & $\begin{array}{l}\text { Little effect in asthma } \\
\text { Reduced allergen } \\
\text { responses in asthma }\end{array}$ & $\begin{array}{c}\text { Development halted } \\
\text { In clinical development for asthma }\end{array}$ & $\begin{array}{c}127 \\
15\end{array}$ \\
\hline & Humanized blocking mAb specific for IL-4 (pascolizumab) & NA & In clinical trials for asthma & 128 \\
\hline IL-5 & $\begin{array}{l}\text { Humanized blocking mAb specific for IL-5 (mepolizumab) } \\
\text { mAb targeting the IL-5 receptor (MEDI-563) }\end{array}$ & $\begin{array}{l}\text { No effect in mild asthma } \\
\text { NA }\end{array}$ & $\begin{array}{l}\text { Clinical studies in severe asthma } \\
\text { In development for asthma }\end{array}$ & $\begin{array}{c}17,18 \\
129\end{array}$ \\
\hline IL-6 & Humanized mAb specific for IL-6R (tocilizumab) & NA & Trials in asthma and COPD proposed & 130 \\
\hline IL-9 & Blocking mAb specific for IL-9 (MEDI-528) & NA & In development for asthma & 131 \\
\hline IL-10 & Recombinant cytokine & No effect in asthma & Development halted & NA \\
\hline IL-12 & Recombinant cytokine & No effect in asthma & Development halted & 33 \\
\hline \multirow[t]{2}{*}{ IL-13 } & $\begin{array}{l}\text { Soluble IL-13R } \alpha 2-F c \text { fusion protein } \\
\text { Blocking mAbs specific for IL-13 } \\
\text { (CAT-354, IMA638, and QAX576) }\end{array}$ & $\begin{array}{l}\text { NA } \\
\text { NA }\end{array}$ & $\begin{array}{l}\text { Trials for asthma proposed } \\
\text { In early clinical trials for asthma }\end{array}$ & $\begin{array}{l}\text { NA } \\
132\end{array}$ \\
\hline & Mutated IL-4 (pitrakinra) & $\begin{array}{l}\text { Reduced allergen } \\
\text { responses in asthma }\end{array}$ & In clinical development for asthma & 15 \\
\hline IL-25 & Blocking mAb specific for IL-25 & NA & In development for asthma & 49 \\
\hline IFN- $\alpha$ & Recombinant cytokine & Improved severe asthma & Clinical development uncertain & 30 \\
\hline IFN- $\gamma$ & Recombinant cytokine & No effect in asthma & Development halted & 26 \\
\hline TNF- $\alpha$ & $\begin{array}{l}\text { Human soluble TNFR-human IgG1Fc } \\
\text { fusion protein (etanercept) }\end{array}$ & Some effect in severe asthma & Studies in severe asthma ongoing & 52 \\
\hline TNF- $\alpha$ & $\begin{array}{l}\text { Chimeric blocking mAb specific } \\
\text { for TNF- } \alpha \text { (infliximab) }\end{array}$ & $\begin{array}{l}\text { Small effect in moderate asthma } \\
\text { No effect in COPD }\end{array}$ & Study in severe asthma completed & $53,55,56$ \\
\hline CXCL8 & $\begin{array}{l}\text { Blocking mAb specific for CXCL8 (ABX-IL8) } \\
\text { CXCR2 antagonists (e.g., PS433540) }\end{array}$ & $\begin{array}{l}\text { Small effect in COPD } \\
\text { NA }\end{array}$ & $\begin{array}{l}\text { Development halted } \\
\text { In early clinical trials for COPD }\end{array}$ & $\begin{array}{l}133 \\
134\end{array}$ \\
\hline
\end{tabular}

IgG1Fc, Fc portion of IgG1; IL-6R, $\alpha$-chain of the receptor for IL-6; IL-13R $\alpha 2$; $\alpha 2$-chain of the receptor for IL-13.

CX3CL1 is chemotactic for monocytes, T cells, and mast cells and also functions as an adhesion molecule in its membrane-bound form (110). CX3CL1 is increased in BAL fluid after allergen challenge of asthmatic patients and shows increased expression on epithelial and endothelial cells (111).

\section{Antiinflammatory cytokines}

Although most cytokines increase or orchestrate the inflammation process in asthma and COPD, some cytokines have inhibitory or antiinflammatory effects. As discussed above, IL-12, through the release of IFN- $\gamma$ from Th1 cells, can suppress Th2 cytokine release and allergic inflammation. TGF- $\beta$ has potential immunomodulatory effects though inhibition of $\mathrm{CD} 4^{+} \mathrm{T}$ cells (73) but does not have therapeutic potential in view of its profibrotic actions.

IL-10 is a potent antiinflammatory cytokine that inhibits the synthesis of many inflammatory proteins, including several cytokines (such as TNF- $\alpha$, GM-CSF, IL-5, and several chemokines) that are overexpressed in asthma and COPD, and also inhibits antigen presentation (112). There is a reduction in IL10 transcription and secretion from macrophages in individuals who have asthma (113). IL-10 is produced by a subset of Tregs and by macrophages (114). Specific allergen immunotherapy results in increased production of IL-10-producing Tregs (115). IL-10 might also be beneficial in COPD as it not only inhibits the production of TNF- $\alpha$ and chemokines, but also MMP-9, which may be involved in the destruction of lung elastin. IL-10 concentrations are reduced in sputum of COPD patients (116).

\section{Therapeutic implications}

Although there have been several attempts to inhibit specific cytokines in asthma and COPD with blocking antibodies (Table 2), the results have so far been disappointing, as so many cytokines are involved and there is considerable redundancy in their effects (117).

Cytokine inhibitors. There is hope that blocking the cytokines that are more upstream in the cytokine cascade that results in either asthma or COPD, such as TSLP and IL-13 for asthma, may produce clinical benefit. It may also be possible to block more than one cytokine with multifunctional domain antibodies. In individuals with mild asthma, an inhaled antisense oligonucleotide combination that blocks CCR3 and the common $\beta$-chain of GM-CSF, IL-3, and IL-5 reduced the expression of the genes encoding these cytokines in airway cells after allergen challenge, with a significant reduction in sputum eosinophils, reduction in early response, and a nonsignificant reduction in late response (118). There is a search for small molecule antagonists, but so far this search has only proven successful for chemokines (88). Drugs that have a an effect on the synthesis of several cytokines may be more successful than inhibitors of specific cytokines or their receptors. 
Corticosteroids. Corticosteroids are by far the most effective treatments for asthma, and a large part of their efficacy is due to inhibition of inflammatory cytokine gene expression. However, they are not effective in suppressing cytokines in COPD (the mechanisms of steroid resistance are reviewed in detail in ref. 119).

Immunomodulators. Cyclosporin A, tacrolimus, and rapamycin inhibit NFAT, which regulates the transcription of genes that encode Th2 cytokines. For example, cyclosporin and tacrolimus inhibit the transcription of IL5 in human T cells in vitro (120). However, although cyclosporin A has some reported beneficial steroid-sparing effects in asthma, its toxicity limits its usefulness when given orally. Although $\mathrm{T}$ cells are prominent inflammatory cells in COPD, no studies of immunomodulators have been reported.

Phosphodiesterase 4 inhibitors. Phosphodiesterase 4 (PDE4) inhibitors block the release of cytokines and chemokines from inflammatory cells by increasing levels of intracellular cAMP. However, their clinical use is limited in asthma and COPD by side effects such as nausea (121).

$N F-\kappa B$ inhibitors. NF- $\kappa B$ regulates the expression of many genes encoding cytokines and chemokines involved in airway diseases. Although there are several possible approaches to inhibition of NF- $\mathrm{B}$, small molecule inhibitors of IKK2 are the most promising (122). An IKK2 inhibitor reduces the expression of IL-1 $\beta$ and TNF- $\alpha$ in rat lungs after exposure to inhaled LPS (123). Although several IKK2 inhibitors are in development, none have been tested in patients with either asthma or COPD. One concern about longterm inhibition of NF-KB is that effective inhibitors may result in immune suppression and impair host defenses, since mice which lack NF- $\mathrm{B}$ genes succumb to septicemia.

p38 MAPK inhibitors. The p38 MAPK pathway is involved in expression of inflammatory cytokines and chemokines (122). A potent inhibitor of $\mathrm{p} 38-\alpha$ isoform, SD-282, inhibits TNF- $\alpha$ release from human lung macrophages in vitro (124) and is also effective in suppressing inflammation, including reduction of IL- 6 concentrations, in a smoking model of COPD in mice in which corticosteroids are ineffective (125). Several p38 MAPK inhibitors have now entered clinical trials for asthma and COPD, but there have been problems of side effects and toxicity, indicating that it is probably necessary to deliver these drugs by inhalation to reduce systemic exposure.

\section{Summary}

Cytokine networks play a key role in orchestrating the inflammation of asthma and COPD, and differences in cytokine patterns that are involved in cell recruitment and in the regulation of $\mathrm{T}$ cells account for the different patterns of inflammation between these diseases. Proinflammatory cytokines, such as TNF- $\alpha$ and IL-6, are involved in both asthma and COPD and may play a role in amplifying inflammation and thus determining disease severity. Growth factors are responsible for the persistence of certain inflammatory cells and for the structural changes that occur in the lungs of patients with asthma and COPD. Blocking specific cytokines or their receptors has so far been disappointing in clinical studies, suggesting that a broader spectrum of antiinflammatory effects is needed. While this is provided by corticosteroids in mild and moderate asthma, alternative antiinflammatory approaches need to be developed to treat individuals with severe asthma and COPD, for which corticosteroids are much less effective.

Address correspondence to: P.J. Barnes, Airway Disease Section, National Heart and Lung Institute, Dovehouse St., London SW3 6LY, United Kingdom. Phone: 44-207-351-8174; Fax: 44-207-3515675; E-mail: p.j.barnes@imperial.ac.uk.
1. Barnes, P.J. 2008. Immunology of asthma and chronic obstructive pulmonary disease. Nat. Rev. Immunol. 8:183-192.

2. Hogg, J.C., et al. 2004. The nature of small-airway obstruction in chronic obstructive pulmonary disease. N. Engl. J. Med. 350:2645-2653

3. Ho, I.C., and Pai, S.Y. 2007. GATA-3 - not just for Th2 cells anymore. Cell. Mol. Immunol. 4:15-29.

4. Caramori, G., et al. 2001. Expression of GATA family of transcription factors in T-cells, monocytes and bronchial biopsies. Eur. Respir. J. 18:466-473.

5. Maneechotesuwan, K., et al. 2007. Regulation of Th2 cytokine genes by p38 MAPK-mediated phosphorylation of GATA-3. J. Immunol. 178:2491-2498.

6. Carriere, V., et al. 2007. IL-33, the IL-1-like cytokine ligand for ST2 receptor, is a chromatin-associated nuclear factor in vivo. Proc. Natl.Acad. Sci. U. S. A 104:282-287.

7. Komai-Koma, M., et al. 2007. IL-33 is a chemoattractant for human Th2 cells. Eur. J. Immunol. 37:2779-2786.

8. Barczyk, A., et al. 2006. Cytokine production by bronchoalveolar lavage $\mathrm{T}$ lymphocytes in chronic obstructive pulmonary disease. J. Allergy Clin. Immunol. 117:1484-1492.

9. Wills-Karp, M. 2004. Interleukin-13 in asthma pathogenesis. Immunol. Rev. 202:175-90.

10. Kuperman, D.A., et al. 2002. Direct effects of interleukin-13 on epithelial cells cause airway hyperreactivity and mucus overproduction in asthma. Nat. Med. 8:885-889.

11. Zhu, Z., et al. 2004. Acidic mammalian chitinase in asthmatic Th2 inflammation and IL-13 pathway activation. Science. 304:1678-1682.
12. Boutten, A., et al. 2004. Decreased expression of interleukin 13 in human lung emphysema. Thorax. 59:850-854.

13. Kroegel, C., Julius, P., Matthys, H., Virchow, J.C., Jr., and Luttmann, W. 1996. Endobronchial secretion of interleukin-13 following local allergen challenge in atopic asthma: relationship to interleukin-4 and eosinophil counts. Eur. Respir. J. 9:899-904.

14. Chupp, G.L., et al. 2007. A chitinase-like protein in the lung and circulation of patients with severe asthma. N. Engl. J. Med. 357:2016-2027.

15. Wenzel, S., Wilbraham, D., Fuller, R., Getz, E.B., and Longphre, M. 2007. Effect of an interleukin-4 variant on late phase asthmatic response to allergen challenge in asthmatic patients: results of two phase 2a studies. Lancet. 370:1422-1431.

16. Stirling, R.G., van Rensen, E.L., Barnes, P.J., and Chung, K.F. 2001. Interleukin-5 induces CD34(+) eosinophil progenitor mobilization and eosinophil CCR3 expression in asthma. Am. J. Respir. Crit. Care Med. 164:1403-1409.

17. Flood-Page, P., et al. 2007. A study to evaluate safety and efficacy of mepolizumab in patients with moderate persistent asthma. Am. J. Respir. Crit. Care Med. 176:1062-1071.

18. Flood-Page, P.T., Menzies-Gow, A.N., Kay, A.B., and Robinson, D.S. 2003. Eosinophil's role remains uncertain as anti-interleukin-5 only partially depletes numbers in asthmatic airways. Am. J. Respir. Crit. Care Med. 167:199-204.

19. Zhou, Y., McLane, M., and Levitt, R.C. 2001. Interleukin- 9 as a therapeutic target for asthma. Respir. Res. 2:80-84

20. Steenwinckel, V., et al. 2007. IL-13 mediates in vivo IL-9 activities on lung epithelial cells but not on hematopoietic cells. J. Immunol. 178:3244-3251.

21. Finotto, S., et al. 2002. Development of spontaneous airway changes consistent with human asthma in mice lacking T-bet. Science. 295:336-338.

22. Hwang, E.S., Szabo, S.J., Schwartzberg, P.L., and Glimcher, L.H. 2005. T helper cell fate specified by kinase-mediated interaction of T-bet with GATA-3. Science. 307:430-433.

23. Usui, T., et al. 2006. T-bet regulates Th1 responses through essential effects on GATA-3 function rather than on IFNG gene acetylation and transcription. J. Exp. Med. 203:755-766.

24. Grumelli, S., et al. 2004. An immune basis for lung parenchymal destruction in chronic obstructive pulmonary disease and emphysema. PLoS Med. 1:e8.

25. Kumar, R.K., Webb, D.C., Herbert, C., and Foster, P.S. 2006. Interferon-gamma as a possible target in chronic asthma. Inflamm. Allergy Drug Targets. 5:253-256.

26. Szabo, S.J., et al. 2002. Distinct effects of T-bet in TH1 lineage commitment and IFN-gamma production in CD4 and CD8 T cells. Science. 295:338-342.

27. Di Stefano, A., et al. 2004. STAT4 activation in smokers and patients with chronic obstructive pulmonary disease. Eur. Respir. J. 24:78-85.

28. Wark, P.A., et al. 2005. Asthmatic bronchial epithelial cells have a deficient innate immune response to infection with rhinovirus. J. Exp. Med. 201:937-947.

29. Contoli, M., et al. 2006. Role of deficient type III interferon-lambda production in asthma exacerbations. Nat. Med. 12:1023-1026.

30. Simon, H.U., Seelbach, H., Ehmann, R., and Schmitz, M. 2003. Clinical and immunological 
effects of low-dose IFN-alpha treatment in patients with corticosteroid-resistant asthma. Allergy. 58:1250-1255.

31. Trinchieri, G., Pflanz, S., and Kastelein, R.A. 2003. The IL-12 family of heterodimeric cytokines: new players in the regulation of $\mathrm{T}$ cell responses. Immunity. 19:641-644.

32. van der Pouw Kraan, T.C., et al. 1997. Reduced production of IL-12 and IL-12-dependent IFN-gamma release in patients with allergic asthma. J. Immunol. 158:5560-5565.

33. Bryan, S., et al. 2000. Effects of recombinant human interleukin-12 on eosinophils, airway hyperreactivity and the late asthmatic response. Lancet. 356:2149-2153.

34. Cooper, A.M., and Khader, S.A. 2007. IL-12p40: an inherently agonistic cytokine. Trends Immunol. 28:33-38.

35. Dinarello, C.A. 2007. Interleukin-18 and the pathogenesis of inflammatory diseases. Semin. Nephrol. 27:98-114.

36. Imaoka, H., et al. 2008. Interleukin-18 production and pulmonary function in COPD. Eur. Respir. J. 31:287-297.

37. Owaki, T., et al. 2005. A role for IL-27 in early regulation of Th1 differentiation. J. Immunol. 175:2191-2200.

38. Yoshimoto, T., Yoshimoto, T., Yasuda, K., Mizuguchi, J., and Nakanishi, K. 2007. IL-27 suppresses Th2 cell development and Th 2 cytokines production from polarized Th2 cells: a novel therapeutic way for Th2-mediated allergic inflammation. J. Immunol. 179:4415-4423.

39. Manel, N., Unutmaz, D., and Littman, D.R. 2008. The differentiation of human $\mathrm{T}(\mathrm{H})-17$ cells requires transforming growth factor-beta and induction of the nuclear receptor RORgammat. Nat. Immunol. 9:641-649.

40. Volpe, E., et al. 2008. A critical function for transforming growth factor-beta, interleukin 23 and proinflammatory cytokines in driving and modulating human $\mathrm{T}(\mathrm{H})-17$ responses. Nat. Immunol. 9:650-657.

41. Bullens, D.M., et al. 2006. IL-17 mRNA in sputum of asthmatic patients: linking $\mathrm{T}$ cell driven inflammation and granulocytic influx? Respir. Res. 7:135.

42. Pene, J., et al. 2008. Chronically inflamed human tissues are infiltrated by highly differentiated th17 lymphocytes. J. Immunol. 180:7423-7430.

43. Dragon, S., et al. 2007. IL-17 enhances IL-1betamediated CXCL-8 release from human airway smooth muscle cells. Am. J. Physiol. Lung Cell Mol. Physiol. 292:L1023-L1029.

44. Schmidt-Weber, C.B., Akdis, M., and Akdis, C.A. 2007. TH17 cells in the big picture of immunology. J. Allergy Clin. Immunol. 120:247-254.

45. Chen, Y., et al. 2003. Stimulation of airway mucin gene expression by interleukin (IL)-17 through IL-6 paracrine/autocrine loop. J. Biol.Chem. 278:17036-17043.

46. Nurieva, R., et al. 2007. Essential autocrine regulation by IL- 21 in the generation of inflammatory T cells. Nature. 448:480-483.

47. Fort, M.M., et al. 2001. IL-25 induces IL-4, IL-5, and IL-13 and Th2-associated pathologies in vivo. Immunity. 15:985-995.

48. Wang, Y.H., et al. 2007. IL-25 augments type 2 immune responses by enhancing the expansion and functions of TSLP-DC-activated Th2 memory cells. J. Exp. Med. 204:1837-1847.

49. Ballantyne, S.J., et al. 2007. Blocking IL-25 prevents airway hyperresponsiveness in allergic asthma. J. Allergy Clin. Immunol. 120:1324-1331.

50. Thomas, P.S., Yates, D.H., and Barnes, P.J. 1995. Tumor necrosis factor- $\alpha$ increases airway responsiveness and sputum neutrophils in normal human subjects. Am. J. Respir. Crit. Care Med. 152:76-80.

51. Kips, J.C., Tavernier, J.H., Joos, G.F., Peleman,
R.A., and Pauwels, R.A. 1993. The potential role of tumor necrosis factor $\alpha$ in asthma. Clin. Exp. Allergy. 23:247-250.

52. Berry, M.A., et al. 2006. Evidence of a role of tumor necrosis factor alpha in refractory asthma. N. Engl. J. Med. 354:697-708.

53. Erin, E.M., et al. 2006. The effects of a monoclonal antibody directed against tumour necrosis factor-alpha in asthma. Am. J. Respir. Crit. Care Med. 174:753-762.

54. Aaron, S.D., et al. 2001. Granulocyte inflammatory markers and airway infection during acute exacerbation of chronic obstructive pulmonary disease. Am. J. Respir. Crit. Care Med. 163:349-355.

55. Rennard, S.I., et al. 2007. The safety and efficacy of infliximab in moderate-to-severe chronic obstructive pulmonary disease. Am.J. Respir. Crit. Care Med. 175:926-934.

56. Dentener, M.A., et al. 2008. Effect of infliximab on local and systemic inflammation in chronic obstructive pulmonary disease: a pilot study. Respiration. 76:275-282. doi:10.1159/000117386.

57. Rosenwasser, L.J. 1998. Biologic activities of IL-1 and its role in human disease. J. Allergy Clin. Immunol. 102:344-350.

58. Culpitt, S.V., et al. 2003. Impaired inhibition by dexamethasone of cytokine release by alveolar macrophages from patients with chronic obstructive pulmonary disease. Am. J. Respir. Crit. Care Med. 167:24-31.

59. Erin, E.M., et al. 2008. Rapid anti-inflammatory effect of inhaled ciclesonide in asthma: a randomised, placebo-controlled study. Chest. Online publication ahead of print. doi:10.1378/chest.07-2575.

60. Bhowmik, A., Seemungal, T.A., Sapsford, R.J., and Wedzicha, J.A. 2000. Relation of sputum inflammatory markers to symptoms and lung function changes in COPD exacerbations. Thorax 55:114-120.

61. Ying, S., et al. 2005. Thymic stromal lymphopoietin expression is increased in asthmatic airways and correlates with expression of Th2-attracting chemokines and disease severity. J. Immunol. 174:8183-8190.

62. Allakhverdi, Z., et al. 2007. Thymic stromal lymphopoietin is released by human epithelial cells in response to microbes, trauma, or inflammation and potently activates mast cells. J. Exp. Med. 204:253-258.

63. Liu, Y.J., et al. 2007. TSLP: an epithelial cell cytokine that regulates $\mathrm{T}$ cell differentiation by conditioning dendritic cell maturation. Annu. Rev. Immunol. 25:193-219.

64. Seshasayee, D., et al. 2007. In vivo blockade of OX40 ligand inhibits thymic stromal lymphopoietin driven atopic inflammation. J. Clin. Invest. 117:3868-3878.

65. Gajewska, B.U., Wiley, R.E., and Jordana, M. 2003. GM-CSF and dendritic cells in allergic airway inflammation: basic mechanisms and prospects for therapeutic intervention. Curr. Drug Targets Inflamm. Allergy. 2:279-292.

66. Balbi, B., et al. 1997. Increased bronchoalveolar granulocytes and granulocyte/macrophage colonystimulating factor during exacerbations of chronic bronchitis. Eur. Respir. J. 10:846-850.

67. Reber, L., Da Silva, C.A., and Frossard, N. 2006. Stem cell factor and its receptor c-Kit as targets for inflammatory diseases. Eur. J. Pharmacol. 533:327-340.

68. Berlin, A.A., Lincoln, P., Tomkinson, A., and Lukacs, N.W. 2004. Inhibition of stem cell factor reduces pulmonary cytokine levels during allergic airway responses. Clin. Exp. Immunol. 136:15-20.

69. Berlin, A.A., and Lukacs, N.W. 2005. Treatment of cockroach allergen asthma model with imatinib attenuates airway responses. Am. J. Respir. Crit. Care Med. 171:35-39.

70. Olsson, N., Rak, S., and Nilsson, G. 2000. Demonstration of mast cell chemotactic activity in bron- choalveolar lavage fluid collected from asthmatic patients before and during pollen season. J. Allergy Clin. Immunol. 105:455-461.

71. Freund-Michel, V., and Frossard, N. 2008. The nerve growth factor and its receptors in airway inflammatory diseases. Pharmacol. Ther. 117:52-76.

72. Nassenstein, C., Kutschker, J., Tumes, D., and Braun, A. 2006. Neuro-immune interaction in allergic asthma: role of neurotrophins. Biochem. Soc. Trans. 34:591-593.

73. Wan, Y.Y., and Flavell, R.A. 2007. Regulatory T cells, transforming growth factor-beta, and immune suppression. Proc. Am. Thorac. Soc. 4:271-276.

74. Minshall, E.M., et al. 1997. Eosinophil-associated TGF-beta 1 mRNA expression and airways fibrosis in bronchial asthma. Am. J. Respir.Cell Mol. Biol. 17:326-333.

75. Balzar, S., et al. 2005. Increased TGF-beta 2 in severe asthma with eosinophilia. J. Allergy Clin. Immunol. 115:110-117.

76. de Boer, W.I., et al. 1998. Transforming growth factor beta 1 and recruitment of macrophages and mast cells in airways in chronic obstructive pulmonary disease. Am. J. Respir. Crit. Care Med. 158:1951-1957.

77. Takizawa, H., et al. 2001. Increased expression of transforming growth factor-beta1 in small airway epithelium from tobacco smokers and patients with chronic obstructive pulmonary disease (COPD). Am. J. Respir. Crit. Care Med. 163:1476-1483.

78. Wang, I.M., et al. 2008. Gene expression profiling in patients with chronic obstructive pulmonary disease and lung cancer. Am. J. Respir. Crit. Care Med. 177:402-411.

79. Ning, W., et al. 2004. Comprehensive gene expression profiles reveal pathways related to the pathogenesis of chronic obstructive pulmonary disease. Proc. Natl. Acad. Sci. U. S. A. 101:14895-14900.

80. Shao, M.X., and Nadel, J.A. 2005. Neutrophil elastase induces MUC5AC mucin production in human airway epithelial cells via a cascade involving protein kinase $\mathrm{C}$, reactive oxygen species, and TNF-alpha-converting enzyme. J. Immunol. 175:4009-4016.

81. Takeyama, K., Fahy, J.V., and Nadel, J.A. 2001. Relationship of epidermal growth factor receptors to goblet cell production in human bronchi. Am.J. Respir. Crit. Care Med. 163:511-516.

82. de Boer, W.I., et al. 2006. Expression of epidermal growth factors and their receptors in the bronchial epithelium of subjects with chronic obstructive pulmonary disease. Am. J. Clin. Pathol. 125:184-192.

83. Siddiqui, S., et al. 2007. Vascular remodeling is a feature of asthma and nonasthmatic eosinophilic bronchitis. J. Allergy Clin. Immunol. 120:813-819.

84. Feltis, B.N., et al. 2006. Increased vascular endothelial growth factor and receptors: relationship to angiogenesis in asthma. Am. J. Respir.Crit. Care Med. 173:1201-1207.

85. Kanazawa, H., Asai, K., Hirata, K., and Yoshikawa, J. 2003. Possible effects of vascular endothelial growth factor in the pathogenesis of chronic obstructive pulmonary disease. Am. J. Med. 114:354-358.

86. Kasahara, Y., et al. 2000. Inhibition of VEGF receptors causes lung cell apoptosis and emphysema. J. Clin. Invest. 106:1311-1319.

87. Lukacs, N.W., Hogaboam, C.M., and Kunkel, S.L. 2005. Chemokines and their receptors in chronic pulmonary disease. Curr. Drug Targets Inflamm. Allergy. 4:313-317.

88. Donnelly, L.E., and Barnes, P.J. 2006. Chemokine receptors as therapeutic targets in chronic obstructive pulmonary disease. Trends Pharmacol. Sci. 27:546-553.

89. de Boer, W.I., et al. 2000. Monocyte chemoattractant protein 1 , interleukin 8 , and chronic airways inflammation in COPD. J. Pathol. 190:619-626.

90. Traves, S.L., Culpitt, S., Russell, R.E.K., Barnes, P.J., 
and Donnelly, L.E. 2002. Elevated levels of the chemokines GRO- $\alpha$ and MCP- 1 in sputum samples from COPD patients. Thorax. 57:590-595.

91. Ying, S., et al. 1999. Eosinophil chemotactic chemokines (eotaxin, eotaxin-2, RANTES, monocyte chemoattractant protein-3 (MCP-3), and MCP-4), and $\mathrm{C}-\mathrm{C}$ chemokine receptor 3 expression in bronchial biopsies from atopic and nonatopic (Intrinsic) asthmatics. J. Immunol. 163:6321-6329.

92. Dorman, S.C., et al. 2005. Progenitor egress from the bone marrow after allergen challenge: role of stromal cell-derived factor $1 \mathrm{alpha}$ and eotaxin. J. Allergy Clin. Immunol. 115:501-507.

93. Ravensberg, A.J., et al. 2005. Eotaxin-2 and eotaxin3 expression is associated with persistent eosinophilic bronchial inflammation in patients with asthma after allergen challenge. J. Allergy Clin. Immunol. 115:779-785.

94. Bocchino, V., et al. 2002. Eotaxin and CCR3 are upregulated in exacerbations of chronic bronchitis. Allergy. 57:17-22

95. Pilette, C., Francis, J.N., Till, S.J., and Durham, S.R 2004. CCR4 ligands are up-regulated in the airways of atopic asthmatics after segmental allergen challenge. Eur. Respir. J. 23:876-884.

96. Di Stefano, A., et al. 2001. Decreased T lymphocyte infiltration in bronchial biopsies of subjects with severe chronic obstructive pulmonary disease. Clin. Exp. Allergy. 31:893-902.

97. Costa, C., et al. 2008. CXCR3 and CCR5 chemokines in the induced sputum from patients with COPD. Chest. 133:26-33.

98. Zhu, J., et al. 2001. Exacerbations of Bronchitis: bronchial eosinophilia and gene expression for interleukin-4, interleukin-5, and eosinophil chemoattractants. Am. J. Respir. Crit. Care Med. 164:109-116

99. Berkman, N., et al. 1996. Expression of RANTES mRNA and protein in airways of patients with mild asthma. Am. J. Respir. Crit. Care Med. 154:1804-1811.

100.Qiu, Y., et al. 2003. Biopsy neutrophilia, chemokine and receptor gene expression in severe exacerbations of COPD. Am. J. Respir. Crit. Care Med. 168:968-975

101.Hay, D.W.P., and Sarau, H.M. 2001. Interleukin-8 receptor antagonists in pulmonary diseases. Curr. Opin. Pharmacol. 1:242-247.

102.Jatakanon, A., et al. 1999. Neutrophilic inflammation in severe persistent asthma. Am. J. Respir. Crit. Care Med. 160:1532-1539.

103.Norzila, M.Z., Fakes, K., Henry, R.L., Simpson, J., and Gibson, P.G. 2000. Interleukin-8 secretion and neutrophil recruitment accompanies induced sputum eosinophil activation in children with acute asthma. Am. J. Respir. Crit. Care Med. 161:769-774.

104. Saetta, M., et al. 2002. Increased expression of the chemokine receptor CXCR3 and its ligand CXCL10 in peripheral airways of smokers with chronic obstructive pulmonary disease. Am. J. Respir. Crit.
Care Med. 165:1404-1409.

105.Brightling, C.E., et al. 2005. The CXCL10/CXCR3 axis mediates human lung mast cell migration to asthmatic airway smooth muscle. Am. J. Respir. Crit. Care Med. 171:1103-1108.

106.Thomas, S.Y., Banerji, A., Medoff, B.D., Lilly, C.M., and Luster, A.D. 2007. Multiple chemokine receptors, including CCR6 and CXCR3, regulate antigen-induced $\mathrm{T}$ cell homing to the human asthmatic airway. J. Immunol. 179:1901-1912.

107. Xanthou, G., Duchesnes, C.E., Williams, T.J., and Pease, J.E. 2003. CCR3 functional responses are regulated by both CXCR3 and its ligands CXCL9, CXCL10 and CXCL11. Eur. J. Immunol. 33:2241-2250.

108.Lukacs, N.W., Berlin, A., Schols, D., Skerlj, R.T., and Bridger, G.J. 2002. AMD3100, a CxCR4 antagonist, attenuates allergic lung inflammation and airway hyperreactivity. Am. J. Pathol. 160:1353-1360.

109.Sukkar, M.B., et al. 2004. Fractalkine/CX3CL1 production by human airway smooth muscle cells: induction by IFN-gamma and TNF-alpha and regulation by TGF-beta and corticosteroids. Am.J. Physiol. Lung Cell Mol. Physiol. 287:L1230-L1240.

110.El Shazly, A., et al. 2006. Fraktalkine produced by airway smooth muscle cells contributes to mast cel recruitment in asthma. J. Immunol. 176:1860-1868.

111. Rimaniol, A.C., et al. 2003. The CX3C chemokine fractalkine in allergic asthma and rhinitis. J. Allergy Clin. Immunol. 112:1139-1146.

112.Pretolani, M., and Goldman, M. 1997. IL-10: a potential therapy for allergic inflammation? Immunol. Today. 18:277-280.

113.John, M., et al. 1998. Inhaled corticosteroids increase IL-10 but reduce MIP-1 $\alpha$, GM-CSF and IFN-g release from alveolar macrophages in asthma. Am. J. Respir. Crit. Care Med. 157:256-262.

114.Hawrylowicz, C.M. 2005. Regulatory T cells and IL-10 in allergic inflammation. J. Exp. Med. 202:1459-1463.

115. Bohle, B., et al. 2007. Sublingual immunotherapy induces IL-10-producing T regulatory cells, allergen-specific T-cell tolerance, and immune deviation. J. Allergy Clin. Immunol. 120:707-713.

116. Takanashi, S., et al. 1999. Interleukin-10 level in sputum is reduced in bronchial asthma, COPD and in smokers. Eur. Respir. J. 14:309-314.

117. Barnes, P.J. 2003. Cytokine-directed therapies for the treatment of chronic airway diseases. Cytokine Growth Factor Rev. 14:511-522.

118.Gauvreau, G.M., et al. 2008. Antisense therapy against CCR3 and the common beta chain attenuates allergen-induced eosinophilic responses. Am.J. Respir. Crit. Care Med. 177:952-958.

119.Barnes, P.J. 2006. How corticosteroids control inflammation. Br. J. Pharmacol. 148:245-254.

120.Rolfe, F.G., Valentine, J.E., and Sewell, W.A. 1997. Cyclosporin A and FK506 reduce interleukin-5 mRNA abundance by inhibiting gene transcription. Am. J. Respir. Cell Mol. Biol. 17:243-250.

121. Chung K.F. 2006. Phosphodiesterase inhibitors in airways disease. Eur. J. Pharmacol. 533:110-117.

122. Barnes, P.J. 2006. Novel signal transduction modulators for the treatment of airway diseases. Pharmacol. Ther. 109:238-245.

123. Birrell, M.A., et al. 2006. IkappaB kinase-2-independent and -dependent inflammation in airway disease models: relevance of IKK-2 inhibition to the clinic. Mol. Pharmacol. 69:1791-1800.

124.Smith, S.J., et al. 2006. Inhibitory effect of p38 mitogen-activated protein kinase inhibitors on cytokine release from human macrophages. $\mathrm{Br}$. J. Pharmacol. 149:393-404.

125.Medicherla, S., et al. 2007. p38 $\alpha$ selective MAP kinase inhibitor, SD-282, reduces inflammation in a sub-chronic model of tobacco smoke-induced airway inflammation. J. Pharmacol. Exp.Ther. 324:921-929.

126. Gram, H., and Di Padova, F.E. 2008. Antibodies to human IL-1 beta. European Patent EP1313769, filed August 20, 2001, and issued May 21, 2008. http:// www.freepatentsonline.com/EP1313769.html.

127. Moseley, B., et al. 1998. Use of interleukin-4 receptors to inhibit biological responses mediated by interleukin-4. US Patent 5767065, filed June 6, 1995, and issued June 16, 1998. http://www.patentstorm.us/patents/5767065/claims.html.

128. Hart, T.K., et al. 2002. Preclinical efficacy and safety of pascolizumab (SB 240683): a humanized antiinterleukin-4 antibody with therapeutic potential in asthma. Clin. Exp. Immunol. 130:93-100.

129.Wilkinson, M. 2007 July 24. MedImmune's antibody gives hope to asthma sufferers. DrugResearcher.com. http://www.drugresearcher. com/news/ng.asp?id $=78451$

130. Roche. 2005 November 17. Actemra monotherapy significantly slows down damage to joints in patients with early aggressive rheumatoid arthritis. Roche media news. http://www.roche.com/med-cor2005-11-17.

131.PR Newswire. 2007 August 19. Phase 2a multi-dose study initiated by MedImmune in patients with asthma to further expand anti-interleukin-9 program. Bio-Medicine.org. http://www.bio-medicine. org/medicine-technology-1/Phase-2a-Multi-DoseStudy-Initiated-by-MedImmune-in-Patients-WithAsthma-to-Further-Expand-Anti-Interleukin-9Program-95-1/.

132.MedImmune. CAT-354. http://www.cambridgeantibody.com/home/products/cambridge_derived products/cat354

133. Henderson, L., Weintraub, B., and Martin, C. 2002. Abgenix cancels development of its anti-IL8 monoclonal antibody. Btech Investor, Inc. http://www. bioportfolio.com/news/btech_051502_1.htm.

134.Sharpless, A.P. 2007 September 25. Pharmacopeia earns milestone payment from Schering-Plough on initiation of Phase 1 clinical trials of novel therapeutic candidate [press release]. Princeton, New Jersey, USA. http://www.pharmacopeia.com/wt/ page/press/pr_1190725994. 